\title{
Introduction \\ How Far Can We Take \\ Strategic Communication? The \\ Sky Is the Limit
}

https://doi.org/10.21814/uminho.ed.46.1

\section{Teresa Ruão', Sara Balonas ${ }^{2}$ and María-Victoria Carrillo ${ }^{3}$}

1,2 Communication and Society Research Centre, Institute of Social Sciences,

University of Minho, Braga, Portugal; ${ }^{3}$ Department of Information and Communication, Faculty of Library and Communication Science, University of Extremadura, Extremadura, Spain ${ }^{1}$ https://orcid.org/0000-0002-9723-8044; ${ }^{2}$ https://orcid.org/0000-0003-0885$1718 ;{ }^{3}$ https://orcid.org/0000-0002-1256-8870 

As a scientific area of knowledge, strategic communication studies are an emerging field within communication sciences and organisational communication research. It is a disciplinary field concerned with the influence of communication in fulfilling the organisational mission - that is, with its "strategic" dimension (van Ruler, 2018). The word "organisation" is used in this book in its broadest sense to refer to companies and institutions, that is, for-profit and non-profit entities, which may include corporations but also activist groups, non-governmental organisations, political parties or movements.

Regardless of the activity area, today's organisations compete heavily for the attention, admiration and loyalty of its stakeholders - such as customers, employees, investors, interest groups, or the general public. For that to happen, different strategic decisions have to be made in finances or human resources, but also in terms of communication. In fact, studies show that the strategic vision on communication improves organisational performance, increases product sales, motivates investors, and builds stronger relationships (Hallahan et al., 2007). In this context, as suggested by Argenti et al. (2005), contemporary organisations face the "strategic communication imperative - an increasingly urgent need for executives to ensure that their communication practices directly contribute to the implementation of the organisational strategy" (p. 83).

Yet the establishment of this scientific field is recent. The International Journal of Strategic Communication in 2007, and the Routledge Handbook of Strategic Communication in 2014 (authored by Zerfass \& Holtzhausen, 2014), have formalised the strategic communication ground. These two reference publications embodied a process of disciplinary affirmation at the beginning of this century, to which followed the exponential growth in the number of papers and books on the subject, as well as the adoption of the "strategic communication" concept to designate undergraduate programs and postgraduate studies, worldwide (Zerfass et al., 2018).

However, after a decade of scientific production, it is time for the academy to debate the current state of research on strategic thinking applied to communication, mainly because the issues that seemed to constrain the establishment of the field have already been widely discussed and overcome. Although some authors continue to argue that the field lacks clarity (Nothhaft et al., 2018), that its disciplinary status remains uncertain (Werder et al., 2018) and that its two main concepts, "communication" and "strategy", are topics that have not, until now, been explored to their full extent (van Ruler, 
2018; Winkler \& Etter, 2018; Zerfass et al., 2018). However, there seems to be widespread recognition of the importance of its insights for the organisational universe.

One of the strongest arguments in this discussion underlines the strength of the interdisciplinary nature of strategic communication, considered even as a condition for the development of the field (Werder et al., 2018). And we could not agree more with this statement, as we see in its interdisciplinary dimension a key requirement for the consolidation of this scientific ground. In fact, strategic communication increasingly requires the contribution of other disciplines, especially when we look at the practices in specific contexts, as evidenced by some of the researchers in this book.

Therefore, we intend, above all, with this publication to analyse strategic communication through the lens of communication sciences but opening up to other academic fields. We therefore emphasise that the basis for communication processes in organisations is the same as that of any human communication activity, for "the essence of the human being is to communicate and receive communication" (Thayer, 1968/1979, p. 35). Furthermore, this book follows the assumption that communication - and organisational communication in particular - always seeks to exert influence and that, following this reasoning, "persuasion is [admittedly] the essence of strategic communication" (Hallahan et al., 2007, p. 24).

As so, the Strategic Communication in Context: Theoretical Debates and Applied Research book has managed to gather up-to-date knowledge regarding the approaches, methodologies and impacts of human communication in organisations of all kinds and contexts. It reveals how strategic communication can express its elasticity when applied to different sectors and environments without losing its vitality. Its foundational principle is actually common to all domains - to help fulfil the organisational mission in a given context. As pointed by Holtzhausen (2008), a communication entity encompasses different types of economic and social contexts, from "trade and industry, politics, non-profit and government agencies, activist groups, and even celebrities in the sports and entertainment industries" (p. 4849). And strategic communication can act on behalf of all these entities.

To be able to discuss this global vision of the field, the book proposes two significant approaches to the strategic communication topic: the first part focuses on major current issues identified by the literature that cross all sectors and contexts, including crisis communication or social practices; 
and the second part explores this scientific domain when applied to different settings, such as development and social change, health, business, science, politics, activist movements, culture, corporate social responsibility, territories, religion or sports. It proposes a kaleidoscopic view through the lens of several researchers who have looked at very different contexts to understand the vitality of the discipline in the quest for solutions that lead to a balanced evolution of societies.

The first part of the book is then devoted to relevant debates on strategic communication. The paper "Strategic Communication Requires Strategic Thinking" written by Peggy Brønn opens the book. Aligning with the approach of the "communicative constitution of organisations", this work describes strategic communication as a fundamental phenomenon for the survival and sustainability of a collective entity. From this standpoint and based on previous research, the author argues that strategic communication needs leaders who are strategic thinkers to be successful. This study concludes that communication executives need to have competencies in strategic thinking to make decisions aligned with the organisation's mission and objectives.

Afterwards, it presents the article "Systematic Review of Recent Literature on Strategic Communication: Analysis of the Scientific Production in Web of Science (2011-2020)". This work, by Javier Trabadela-Robles, brings a systematic review of the most recent scientific output on strategic communication, namely between 2011 and 2020. The main objective of this research was to analyse that output quantitatively, to determine whether the number of publications has grown, from which scientific fields they have originated, the most prolific authors, and the most cited works. Among the results found, it stands out the exponential growth of the scientific production in the field compared to previous periods. Most of the studies are published in English and originate from communication, business, and management. In addition, the authors of such papers are mainly from the USA, Spain, Germany, and England, and they published in 274 journals, with the Journal of Communication Management, Public Relations Review, and Corporate Communications being the ones with more publications in this field.

"Developing Effective Health Communication Campaigns" is the following work, written by Ralph Tench and Gemma Bridge. This chapter discusses the importance of health communication campaigns to address and promote risky behaviour change. However, the authors argue about the need to improve the success of these campaigns to avoid inadvertent social 
norming of risk behaviour. This change highlights the importance of targeting a campaign to the audience, considering this audience in developing and disseminating the message. To analyse these arguments, the authors presented examples of targeted and broad health communication campaigns. The conclusions of this study show that campaigns could also be co-developed with the audience to ensure relevance and that digital technologies, such as machine learning and artificial intelligence, can effectively tailor messages to the target audience.

The study on "Social Movement Activism: Analysis of Strategic Communication in Context", by Robert L. Heath and Damion Waymer, analyses the relationship between social movement activism and strategic communication. The authors argue that social movement activism presumes strategic communication processes by which groups achieve extra-governmental public and private policy changes through public pressure. They present several cases to explain and defend this idea and highlight the USA civil rights movement and the activist career of John Lewis. The writers conclude that language is the essence of strategic communication and that, in the case of social movement activism, terms are an incentive and a means to persuasion as the communities are divided by language.

More on the debate about strategic communication, we suggest the reading of "Crisis Communication as Course Correction: Communicative Efforts Revive Goals", a chapter written by W. Timothy Coombs. This research discusses the relevance of crisis communication. It examines its role beyond the typical function as a reactive form of communication intending to protect an organisation from a threat. For this, the author analyses two theories stealing thunder and situational crisis communication theory - that help managers understand which response strategies are ideal for their specific crisis. The author concludes that crisis communication can be proactive and used as a form of strategic communication designed to guide managers to pursue organisational goals.

Ending the first part of the book, Ivone de Lourdes Oliveira, Fábia Pereira Lima, and Isaura Mourão Generoso share their study about "Mediated Strategic Communication: Meaning Disputes and Social Practice". This research seems to debate the reference models of communication and strategy adopted by organisations, especially in a media society, to outline a new approach to strategic communication. The authors analysed the positioning of organisations during the event of the COVID-19 pandemic in Brazil, examining their interactions and symbolic confrontations in the media 
space. The analysis shows that organisations need to understand media communication production processes and their connections with individual and collective issues, which follow the meanings, discursive practices, and organisational strategies.

The second part of this book presents several texts that discuss strategic communication in context. This section starts with the contribution of Sara Balonas about "Social Change: Bringing Allies to the Field. An Interdisciplinary Model". This work seeks to emphasise the importance of strategic communication on behavioural and effective social change. For this, the author summons participatory communication, social marketing and behavioural sciences to create a strategic communication matrix for social change based on a cross-disciplinary perspective. Finally, the article proposes a working model that articulates the contributions of the mentioned topics that can apply to the communication strategies of sustainable development goals.

Continuing the second part, Teresa Ruão and Sónia Silva presented their study about "Science Strategic Communication: The 'Flatten the 'Curve' Metaphor in COVID-19 Public Risk Messaging". This chapter discusses the emergence of the "flatten the curve" metaphor in the context of COVID-19 science communication strategies and explores several ways in which this curve was used in public messaging efforts that aimed to inform worldwide populations and mitigate the effects of the pandemic. In conclusion, the authors realised that, even though the "flatten the curve" metaphor was not developed in an aligned way (as it resulted from a series of isolated interventions by different social actors), it became a science strategic communication device, able to convey complex information attractively and creatively while being precise, objective and clear to the general public.

The following text is "Strategic Communications and the Toms Case: Aligning Business Strategy With Strategic Communications" by María-Victoria Carrillo and Ana Castillo. In their research, the authors analysed the principles of this scientific field, taking the case of the Toms firm as an example in which business strategy aligns with communication. This case study demonstrates that an organisation wishing to apply communication strategically must articulate its tactics and action plans with its ultimate objectives while maintaining its vision and business mission. In addition, this work concludes that strategic communication is a sub-discipline that today's new business models, rather than the traditional ones, should define. 
The chapter by Emilia Smolak Lozano and Atsuho Nakayama relates strategic communication and politics. Their research drew on the fact that Twitter has become a powerful tool for political communication with a significant role in elections, especially in countries like Spain, where digital media has considerable influence in society. Applying text-mining methods to tweets from the 2019 European elections, the authors analysed the content, frequently used keywords and expressions, sentiment and tone of the political discourse of the leading Spanish political parties. The study aimed to compare the presence of the different political parties on Twitter. The conclusions show the low maturity of democratic public debate and proved that the Spanish political stakeholders could improve their Twitter content and tone.

Furthering this section of the book, "Improvisation Takes a Lot of Planification: Strategic Communication and Sociopolitical Contemporary Activism", is the research presented by Naíde Muller. In this essay, the author argues that strategic communication approaches that successfully established mass consumption as a way of life can give public voice to socio-political-contemporary activists and increase shared global views for social change, such as the Agenda 2030 for sustainable development. To justify this idea, a literature review on this topic is presented, followed by a description of practical examples. The conclusions of this work show that strategic communication plays a crucial role in inducing social change. Its applicability in an organisational context is relevant for activist movements as it facilitates collective action, the call for civic participation and interaction with other social and political institutions.

Afterwards, the study "Communication Strategy for COVID-19 in Uruguay" by Patricia Schroeder and Belén Amadeo focuses on the field of health communication. This research summarises the main communication decisions made by the Uruguayan government and the ministry of public health during the COVID-19 pandemic. Uruguay has managed to minimise the pandemic's adverse effects conveyed to other countries in Latin America through exact health and communication strategies based on transparency and real-time information. The authors analysed this example of health communication and explained how this country implemented its communication strategy, applying conceptual models taken from strategic communication, political communication, and crisis management.

The following is the text "Strategic Communication in Cultural Organizations, the Landscape Museum" by Maria João Centeno. The article explores the role of strategic communication in cultural organisations, presenting 
the Landscape Museum. It seeks to address one aspect of communication: its power to build and maintain relationships or networks through dialogue. According to this principle, the author argues that the museum, as a digital platform, can play an active role in articulating the lifeworld and the political and economic systems by guaranteeing free spaces for dialogical communicative experiences that build the idea of a shared symbolic space. This study concludes that the Landscape Museum, specifically through its educational service, has promoted acceptance through dialogue thus contributing to landscape citizenship.

The chapter "Corporate Social Responsibility and Consumer Brand Advocacy. A Reflection in a Time of Crisis" by Ivone Ferreira, Luís Eusébio, Antonio Raúl Fernández Rincón and Pedro Antonio Hellín Ortuño continues this section. This work discusses the process of stakeholder empowerment in the context of web 2.0 and the consequent loss of control by companies over the dissemination and circulation of information that concerns them. Given the existence of increasingly demanding communities and groups and the relevance that public opinion has on organisational reputation, this research argues that it is essential that organisations adopt ethical and transparent conduct, which will allow them to gain trust and long-term customer support. Thus, the authors conclude that corporate social responsibility (CSR) policies are essential drivers of consumer loyalty to the brand and further online advocacy.

Ana Duarte Melo presents her research named "What's in a Place? The Contribution of Strategic Communication to Placemaking and Territorial Communication" in a different approach" This article, set in territorial communication, summons the various contributions of strategic communication to placemaking and promotion, approaching them both through a mind-frame path, a multi-layered concept, and an operational approach as a practical tool. With some examples, this work reflects on several experiences to illustrate the potential of strategic communication to add value to places in different sets and scales, from building a place almost from scratch to nation branding strategies, from positioning and re-positioning objectives to building up awareness or developing communities' sense of belonging to a territory. In addition, this research traces an evolutionary frame of territorial communication in the light of its strategic dimension, drawing on key concepts and trends, influences, and achievements.

Still, on applying strategic communication, is the work "Conveyed Religion: A Strategic Communication Proposal for Religious Institutions" written by José Gabriel Andrade. Trying to approach how religion can use strategic 
communication in contemporary times starts from the review of a theoretical corpus on religion, communication, and society, crossing reflection with theories of strategic and crisis communication. Analysing religious institutions as living organisations that need to accept the moment we live in to develop a strategic communication plan, this research concludes that the Catholic Church has been showing correct use of new media for strategic communication and that continuous training is vital for the improvement of strategic communication plans.

The value of strategic communication in sport is the theme of the chapter "Communication and Sport: A Call to Action" by Paulo Salgado. This text starts from the assumption that using a strategic communication approach in the sports industry must consider a broader and more profound reflection of how the world of sports intertwines with communication and its interactive process of creation, selection, and retention of meaning. Through his work, the author advocates that studies in sports contexts might contribute to a better understanding of management and communication functions in organisations. Following a close connection between sports, identities, communication, organisations, communities, and media, this study concludes that any strategic communication program must address the singularities of sports organisations.

English revision: Anabela Delgado

\section{Acknowledgements}

This work is supported by national funds through FCT - Fundação para a Ciência e a Tecnologia, I.P., under the project UIDB/00736/2020.

\section{References}

Argenti, P. A., Howell, R. A., \& Beck, K. A. (2005). The strategic communication imperative. MIT Sloan Management Review, 46(3), 83-89. https://sloanreview.mit.edu/article/the-strategic-communication-imperative/

Hallahan, K., Holtzhausen, D., van Ruler, B., Verčič, D., \& Sriramesh, K. (2007). Defining strategic communication. International Journal of Strategic Communication, 1(1), 3-35. https://doi. org/10.1080/15531180701285244

Holtzhausen, D. R. (2008). Strategic communication. In W. Donsbach (Ed.), The international encyclopedia of communication (Vol. 10, pp. 4848-4855). Blackwell Publishing. 
Nothhaft, H., Werder, K. P., Verčič, D., \& Zerfass, A. (2018). Strategic communication: Reflections on an elusive concept. International Journal of Strategic Communication, 12(4), 352-366. https:// doi.org/10.1080/1553118X.2018.1492412

Thayer, L. (1979). Comunicação: Fundamentos e sistemas (E. Nascimento \& S. Coutinho, Trans.). Atlas. (Original work published 1968)

van Ruler, B. (2018). Communication theory: An underrated pillar on which strategic communication rests. International Journal of Strategic Communication, 12(4), 367-381. https://doi.org/1 $0.1080 / 1553118 \times .2018 .1452240$

Werder, K. P., Nothhaft, H., Verčič, D., \& Zerfass, A. (2018). Strategic communication as an emerging interdisciplinary paradigm. International Journal of Strategic Communication, 12(4), 333351. https://doi.org/10.1080/1553118X.2018.1494181

Winkler, P., \& Etter, M. (2018). Strategic communication and emergence: A dual narrative framework. International Journal of Strategic Communication, 12(4), 382 -398. https://doi.org/10.10 $80 / 1553118 \times .2018 .1452241$

Zerfass,A., \& Holtzhausen, D. R. (2014). Routledge handbook of strategic communication. Routledge. Zerfass, A., Verčič, D., Nothhaft, H., \& Werder, K. P. (2018). Strategic communication: Defining the field and its contribution to research and practice. International Journal of Strategic Communication, 12(4), 487-505. https://doi.org/10.1080/1553118X.2018.1493485 